\title{
Development of Fe-9Cr Alloy via High-Energy Ball Milling and Spark Plasma Sintering
}

\author{
ARNAB KUNDU,${ }^{1}$ ANUMAT SITTIHO,${ }^{1}$ INDRAJIT CHARIT,${ }^{1,2,5}$ \\ BRIAN JAQUES, ${ }^{2,3}$ and CHAO JIANG ${ }^{4}$
}

\begin{abstract}
1.-Department of Chemical and Materials Engineering, University of Idaho, Moscow, ID 83844, USA. 2.-Center for Advanced Energy Studies, Idaho Falls, ID 83844, USA. 3.-Department of Material Science and Engineering, Boise State University, Boise, ID 83725, USA. 4.-Idaho National Laboratory, Idaho Falls, ID 83415, USA. 5.-e-mail: icharit@uidaho.edu
\end{abstract}

Iron and chromium powders were mixed and mechanically alloyed via highenergy ball milling for different time durations $(2-20 \mathrm{~h})$ to produce an alloy powder with a nominal composition of $\mathrm{Fe}-9 \mathrm{Cr}$ (wt.\%). The milled $\mathrm{Fe}-9 \mathrm{Cr}$ powders were analyzed using scanning electron microscopy (SEM), x-ray diffraction (XRD) and transmission electron microscopy (TEM) to understand the impact of ball milling (BM) time on the characteristics of the milled powder. The optimized milled powder samples were then consolidated via spark plasma sintering (SPS) for different dwell times and temperatures. The density of consolidated samples was found to reach a maximum of $98 \%$. Microstructural characterization of the SPS samples were performed using XRD, SEM, TEM and electron backscatter diffraction. This study highlights the principles and importance of high-energy BM and SPS of $\mathrm{Fe}-9 \mathrm{Cr}$ model alloy for the future development of more complex oxide dispersion-strengthened alloys for various applications including advanced nuclear reactor applications.

\section{INTRODUCTION}

High-chromium (9-14 wt.\%) alloys are favorable for future sodium fast reactor fuel cladding materials,${ }^{1-3}$ which require high-radiation swelling resistance and resistance to attack from liquid sodium. ${ }^{4}$ Oxide dispersion strengthened (ODS) steels based on $\mathrm{Fe}-(9-14) \% \mathrm{Cr}$ alloys are quite promising for such applications. Generally, the processing routes for fabricating such alloys involve mechanical alloying MA which incorporates rare earth oxides in the Fe$\mathrm{Cr}$ matrix. MA is a processing method that involves repeated fracturing, welding and re-fracturing of a mixture of powder particles to produce a controlled, extremely fine microstructure which cannot be easily produced via conventional ingot metallurgy. The milled powder is consolidated into bulk shapes and heat-treated to obtain the desired characteristics. ${ }^{5}$ It has been reported that the morphology, grain size distribution and contamination of the milled powders strongly depend on the process variables of MA such as milling time, process control agent, ball-to-powder weight ratio, milling atmosphere, etc. ${ }^{6-11}$ Formation of nanostructures during milling has been established as one of the most effective mechanism to increase solid solubility due to a higher fraction of atoms at the grain boundaries and an enhanced diffusion path. ${ }^{12}$

Spark plasma sintering (SPS) is a thermal and pressure-assisted compaction/sintering process. It is also known as the field-assisted sintering technique (FAST) ${ }^{13}$ or pulsed electric current sintering. ${ }^{14}$ This process utilizes a combined action of a pulsed direct electrical current and pressure to perform high-speed consolidation of the powder. The direct method of heating allows for very high heating rates, thus increasing densification due to enhanced diffusion. ${ }^{15-17}$ It is regarded as a rapid sintering method in which the heat is distributed over the volume of the powder compact and dissipates exactly at the contact points of the powder particles. SPS systems offer many advantages over conventional techniques such as hot pressing, hot isostatic pressing (HIP) or pressureless sintering, including the ease of operation and accurate control of sintering energy, resulting in lower-temperature 
sintering and less time, and applicability to both electrically conductive and non-conductive materials.

The Fe-9Cr alloy serves as a base matrix for the Fe-9Cr ODS alloy which has attracted much interest. ${ }^{18,19}$ Even though higher-Cr ODS alloys have better corrosion/oxidation resistance, they often suffer from thermal aging embrittlement and irradiation embrittlement because of alpha-prime phase formation. ${ }^{20}$ However, Fe-9Cr-based ODS steels are relatively free from such effects because of their lower $\mathrm{Cr}$ content. Thus, it is important to understand the $\mathrm{Fe}-9 \mathrm{Cr}$ matrix behavior. $\mathrm{Fe}-9 \mathrm{Cr}$ alloy has been primarily made by casting, ${ }^{21,22}$ but only limited work has been reported on the powder metallurgy-sourced $\mathrm{Fe}-9 \mathrm{Cr}$ alloy. Heintze et al. ${ }^{23}$ conducted high-energy ball milling (BM) followed by SPS and HIP. The present work was taken up to gain an understanding of the effects of the BM and SPS parameters on the microstructure and morphological characteristics and the mechanical properties of $\mathrm{Fe}-9 \mathrm{Cr}$ alloy. An effort has also been made to understand the SPS kinetics.

\section{MATERIALS AND METHODS}

Iron powder $(99.9+\%$ metal basis $)$ of around $10 \mu \mathrm{m}$ size and chromium powder $(99.95 \%$ metal basis) of $50 \mu \mathrm{m}$ size were mixed in ratio of $91: 9$, respectively, and poured into a stainless steel vial without any surfactant along with stainless steel balls (milling medium) of $8 \mathrm{~mm}$ diameter inside an argon atmosphere-controlled glove box to prevent oxidation/contamination. The ball-to-powder weight ratio was around 10:1. ${ }^{24}$ About half of the steel vial was empty after the mixture of powder and steel balls was poured. The filled vials were loaded into a shaker mill (SPEX $8000 \mathrm{M}$ ) and milled for various durations ( $2 \mathrm{~h}, 5 \mathrm{~h}, 8 \mathrm{~h}, 10 \mathrm{~h}, 12 \mathrm{~h}, 15 \mathrm{~h}$, and $20 \mathrm{~h}$ ). The carbon and nitrogen content of the powders were found to be approximately $0.02 \mathrm{wt} . \%$ and 0.024 wt.\%, respectively, estimated using combustion analysis. The chromium content of the 10-h ball-milled sample was estimated by inductively coupled plasma test and found to be $8.97 \mathrm{wt} . \%$ which is essentially the target composition (i.e., 9 wt.\% Cr).

The milled powders were characterized in Zeiss Supra 35 VP field-emission gun scanning electron microscope to examine the powder size and morphology. x-ray diffraction (XRD) of the ball-milled powders was performed using a Siemens 5000D diffractometer with $\mathrm{Cu} K \alpha$ x-ray radiation (wavelength, $0.1541 \mathrm{~nm}$ ). Modifications such as adaptive smooth, $k \alpha_{2}$ Rachinger and background correction by the Sonnerveld method were applied to the XRD patterns using Powder-X software. From the XRD data, the lattice parameter of the milled powders was calculated based on the Nelson-Riley relationship. ${ }^{25}$ The crystallite size and lattice strain were evaluated using the Williamson-Hall equation ${ }^{26}$ :

$$
\beta_{h k l}=0.94\left(l / L \cos \theta_{h k l}\right)+4 \varepsilon \tan \theta_{h k l}
$$

where $\beta_{h k l}$ is the full width half maxima of the XRD peak, $2 \theta_{h k l}$ is the diffraction angle, $L$ is the crystallite size and $\varepsilon$ is the lattice strain. Transmission electron microscopy (TEM) was performed in a JEOL 2010J TEM at an accelerating voltage of $200 \mathrm{kV}$ to study the inherent structure of the $10-\mathrm{h}$ milled powder.

A Dr. Sinter Lab SPS-515S (SPS Syntex, Kanagawa, Japan) available at the Center for Advanced Energy Studies, Idaho Falls, USA, was used to consolidate the milled powder. A Tri-Gemini cylindrical graphite die with an inner diameter of $12.7 \mathrm{~mm}$ and outer diameter of $38 \mathrm{~mm}$ was used. The inner surface of the die was covered with a graphite foil with a thickness of $0.25 \mathrm{~mm}$ to facilitate sample removal. The milled powder was coldcompacted inside the graphite die, and a $0.2-\mathrm{mm}$ thick graphite foil was placed between the powder and transmission electron microscopy punches. The die was wrapped in a 4-mm-thick layer of graphite felt to minimize heat loss by thermal radiation. Degassing was performed by continually purging with argon gas and pumping the chamber down to $9.33 \times 10^{-7} \mathrm{MPa}$, and repeated at least thrice before starting the sintering process. The milled powder batches were heated in the vacuum chamber to four different temperatures $\left(850^{\circ} \mathrm{C}, 950^{\circ} \mathrm{C}\right.$, $1000^{\circ} \mathrm{C}$, and $1050^{\circ} \mathrm{C}$ ) at a rate of $100^{\circ} \mathrm{C} / \mathrm{min}$ and then held for $7 \mathrm{~min}, 15 \mathrm{~min}, 30 \mathrm{~min}$, and $45 \mathrm{~min}$. The temperature was monitored with a K-type thermocouple inserted through a hole in the die. A constant uniaxial pressure of $80 \mathrm{MPa}$ was applied to the milled powder during SPS. The samples were then cooled to room temperature in the SPS chamber at $50^{\circ} \mathrm{C} / \mathrm{min}$. The final product was in the form of a disk with dimensions of $12.5 \mathrm{~mm}$ diameter and $4.8 \mathrm{~mm}$ thickness.

The density of the sintered samples was measured by Archimedes principle. The weight of the samples was taken in air and in fully immersed condition in deionised water using an Ohaus Precision Balance (HRB-200). The density of deionised water $\left(1 \mathrm{~g} / \mathrm{cm}^{3}\right)$ and the density of air $\left(0.0012 \mathrm{~g} / \mathrm{cm}^{3}\right)$ at standard room temperature and pressure were used for density calculations. The theoretical density was taken to be around $7.81 \mathrm{~g} / \mathrm{cm}^{3}$. The relative density was estimated in terms of the percentage of theoretical density.

Vickers microhardness tests were performed using LECO $100 \mathrm{M}$ microhardness tester at a load of $0.5 \mathrm{~kg}$ and a loading time of $15 \mathrm{~s}$ at 10 different random points. All Vickers hardness numbers (VHN) reported in this study are given in the units of $\mathrm{kgf} / \mathrm{mm}^{2}$. The same x-ray diffractometer and TEM were used for analyzing the phase constituents and grain size of the SPS samples. For preparing the TEM specimens, an electro-jet polishing technique was used. A solution of $\mathrm{CH}_{3} \mathrm{OH}-\mathrm{HNO}_{3}$ (80:20, by vol.\%) was used as electrolyte at $-40^{\circ} \mathrm{C}$ and a 
voltage of $25 \mathrm{~V}$ using a Fischione Model 110 TwinJet Electropolisher. Electron backscatter diffraction (EBSD) analysis was carried out with a Thermoscientific Quasor ${ }^{\mathrm{TM}}$ system available in a scanning electron microscopy (SEM) at an accelerating voltage of $20 \mathrm{kV}$ and at a $70^{\circ}$ tilt angle having a resolution of 2 pixels $\times 2$ pixels. Compression testing was performed at room temperature under a strain rate of $10^{-3} \mathrm{~s}^{-1}$ using an Instron 5982 universal tester.

\section{RESULTS AND DISCUSSION}

\section{Microstructural Characteristics of the Milled Fe-9Cr Powders}

The milled powder batches were examined by SEM and TEM (Fig. 1). Figure 1a, b, and c shows the representative SEM images of the powder samples ball-milled for $2 \mathrm{~h}, 10 \mathrm{~h}$, and $20 \mathrm{~h}$, respectively. Powder size analysis revealed that the mean powder size decreased with increasing milling time, as shown in Fig. 1f. Also, it can be noted that the powder size distribution became progressively narrower with increasing milling time. Due to continuous collision of the powder particles with the balls, the powder particles break down into smaller particles. As seen in Fig. 1a, the mean powder size was around $50 \pm 20 \mu \mathrm{m}$ for the powder ball-milled for $2 \mathrm{~h}$. With continued deformation, the powder particles are work-hardened and fractured by fatigue failure or impact fragmentation, ${ }^{27}$ and the minimum powder size is found to be $15 \mu \mathrm{m}$. Figure 1d shows a bright field TEM image while the corresponding selected area diffraction (SAD)
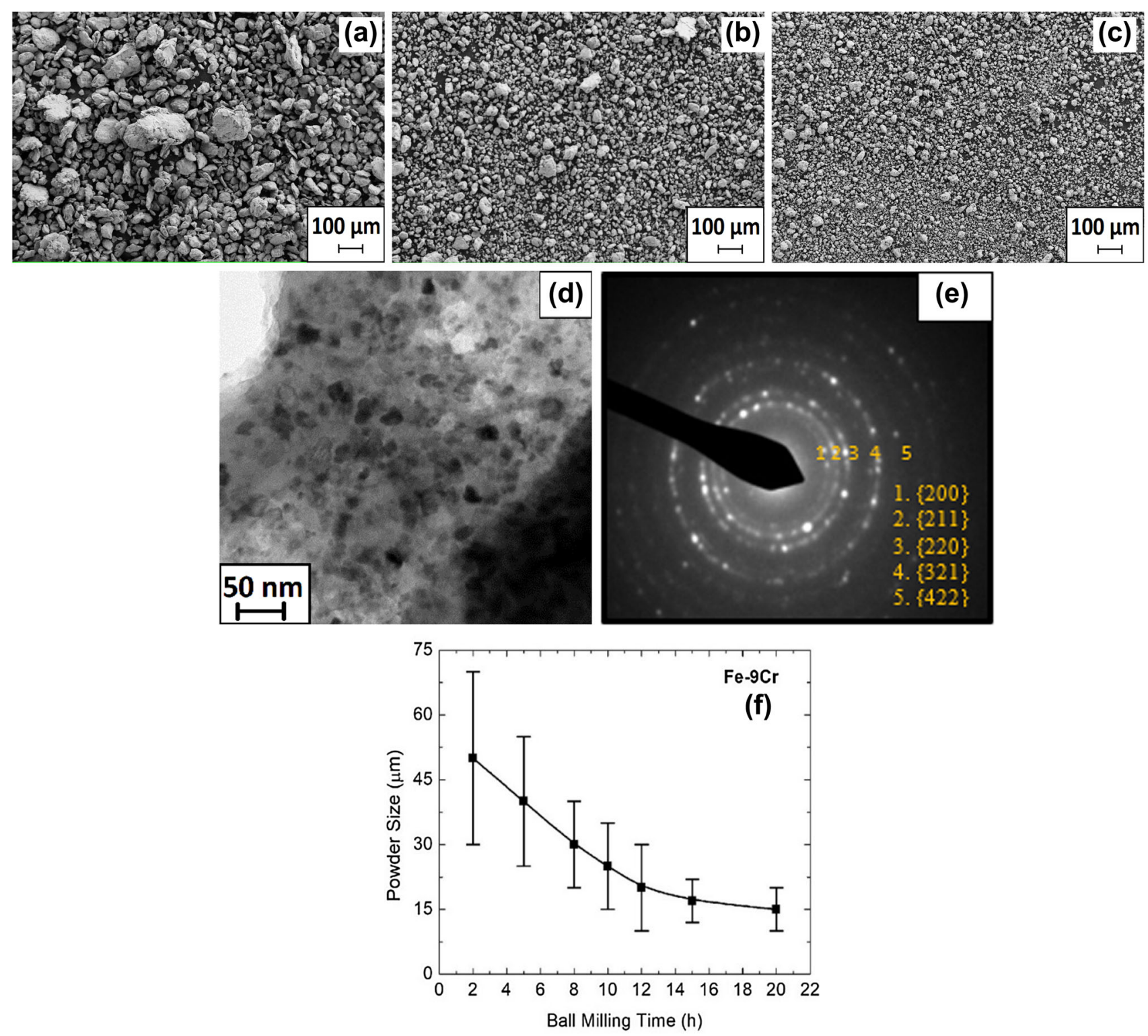

Fig. 1. Secondary electron SEM images of Fe-9Cr powders milled for various time periods: (a) $2 \mathrm{~h}$, (b) $10 \mathrm{~h}$, (c) $20 \mathrm{~h}$. TEM image of (d) $10-\mathrm{h}$ milled and (e) SAD pattern of the $10-\mathrm{h}$ milled powder at $300 \mathrm{~mm}$ camera length. (f) Variation of powder size as a function of milling time. 
pattern of the milled powder is shown in Fig. 1e. The microstructure shows a uniform distribution of nanograins. The crystallite size measurement was carried out using the mean linear intercept method and the average grain size was measured to be around $12 \mathrm{~nm}$, which is consistent with the crystallite size determined from the XRD data $(11.3 \mathrm{~nm})$. The rings in the SAD pattern are from the ferritic matrix phase and no diffraction from any other phases is observed. ${ }^{28}$

Figure 2 shows the XRD patterns of the various milled powder samples. Prominent peaks are observed near the diffraction angles $(2 \theta)$ of $44.91^{\circ}$, $65.46^{\circ}$, and $82.57^{\circ}$. These peaks correspond to the planes $\{110\},\{200\}$, and $\{211\}$ of ferrite (BCC), respectively. ${ }^{29}$

Broadening of the diffraction peaks is also observed with increasing milling time, which can be due to the introduction of strain and decrease of crystallite size of the powders. ${ }^{30}$ A small shift of the peak positions toward the left is seen as a result of the solid solutionizing of $\mathrm{Cr}$ in $\mathrm{Fe}$ and increasing strain during milling.

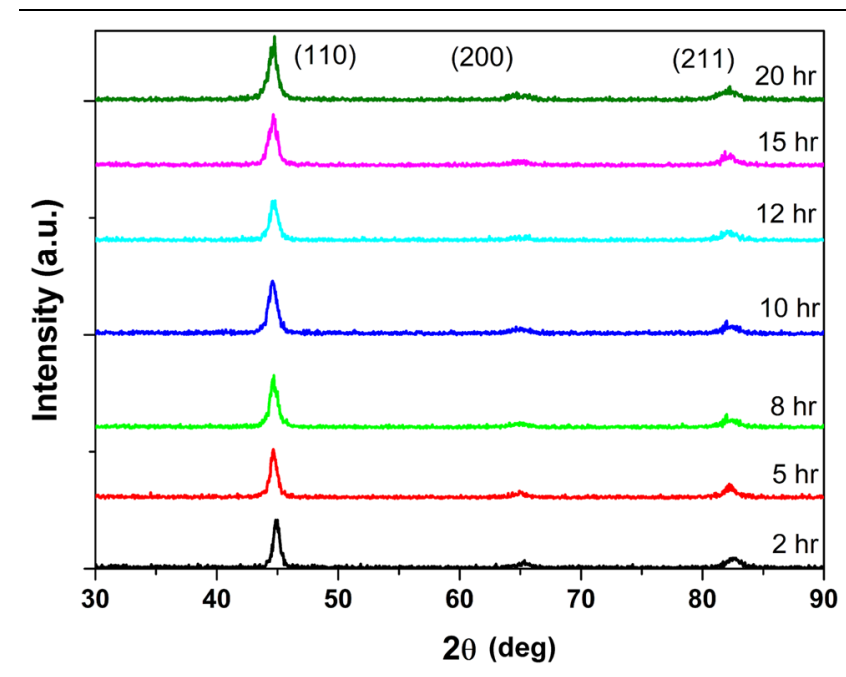

Fig. 2. XRD patterns of $\mathrm{Fe}-9 \mathrm{Cr}$ powder batches milled for various durations.
Table I shows the variation of the lattice parameter, crystallite size and lattice strain with BM time. The lattice parameter on average is $2.880 \pm 0.001 \AA$, which is inbetween those of iron $(2.87 \AA)$ and chromium $(2.89 \AA)$. According to Vegard's Law, ${ }^{31}$ the lattice parameter of Fe-9Cr solid solution is $2.872 \AA$.

The crystallite size decreases with the increase in BM time. High-energy ball-milling being a severe plastic deformation process, the process introduces progressively higher amounts of strain leading to smaller crystallite size with increasing milling time.

\section{Characteristics of Spark Plasma-Sintered Fe- 9Cr Samples}

\section{Evaluation of Density and Microhardness}

The variation of relative density of the sintered samples with sintering time is shown in Fig. 3a. Sintering was conducted for four different dwell times ( $7 \mathrm{~min}, 15 \mathrm{~min}, 30 \mathrm{~min}$, and $45 \mathrm{~min}$ ) at a constant temperature of $950^{\circ} \mathrm{C}$ and an applied pressure of $80 \mathrm{MPa}$. The density of the samples increases with increasing sintering time. The SPS process, being a diffusion-controlled process, allows prolonged duration of diffusion to take place resulting in a progressive decrease in porosity. However, the effect of sintering temperature is found to be more effective on densification. Figure $3 b$ shows the variation of relative density of the sintered samples as a function of sintering temperature. There are four sintering temperatures $\left(850^{\circ} \mathrm{C}, 950^{\circ} \mathrm{C}, 1000^{\circ} \mathrm{C}\right.$, and $1050^{\circ} \mathrm{C}$ ), for which the sintering time and applied pressure were kept the same, i.e. $45 \mathrm{~min}$ and $80 \mathrm{MPa}$, respectively. With increasing sintering temperature, the relative density of the sintered samples increases. Given the diffusional nature of sintering, a higher temperature would lead to greater diffusivity leading to greater densification. However, at a higher sintering temperature $\left(1050^{\circ} \mathrm{C}\right)$, there is a likelihood of additional pore formation due to spark discharge and other factors, which can lead to a slight decrease in density. The maximum density $(97.9 \pm 0.1 \%)$ is obtained for the sample sintered at $1000^{\circ} \mathrm{C}$ for $45 \mathrm{~min}$.

The microhardness of the samples was measured by Vickers microhardness testing. Figure 3c shows

Table I. Lattice parameter, crystallite size and lattice strain of the Fe-9Cr powder batches ball-milled for various durations, as analyzed from the XRD data

\begin{tabular}{|c|c|c|c|}
\hline Ball-milling time (h) & Lattice parameter $(\AA)$ & Crystallite size (nm) & Strain (\%) \\
\hline 2 & $2.871 \pm 0.001$ & $14.91 \pm 0.02$ & $0.64 \pm 0.02$ \\
\hline 5 & $2.882 \pm 0.001$ & $14.66 \pm 0.02$ & $0.66 \pm 0.02$ \\
\hline 8 & $2.881 \pm 0.001$ & $13.27 \pm 0.02$ & $0.72 \pm 0.02$ \\
\hline 10 & $2.891 \pm 0.001$ & $11.34 \pm 0.02$ & $0.84 \pm 0.02$ \\
\hline 12 & $2.882 \pm 0.001$ & $10.97 \pm 0.02$ & $0.87 \pm 0.02$ \\
\hline 15 & $2.872 \pm 0.001$ & $10.69 \pm 0.02$ & $0.89 \pm 0.02$ \\
\hline 20 & $2.881 \pm 0.001$ & $10.35 \pm 0.02$ & $0.92 \pm 0.02$ \\
\hline
\end{tabular}



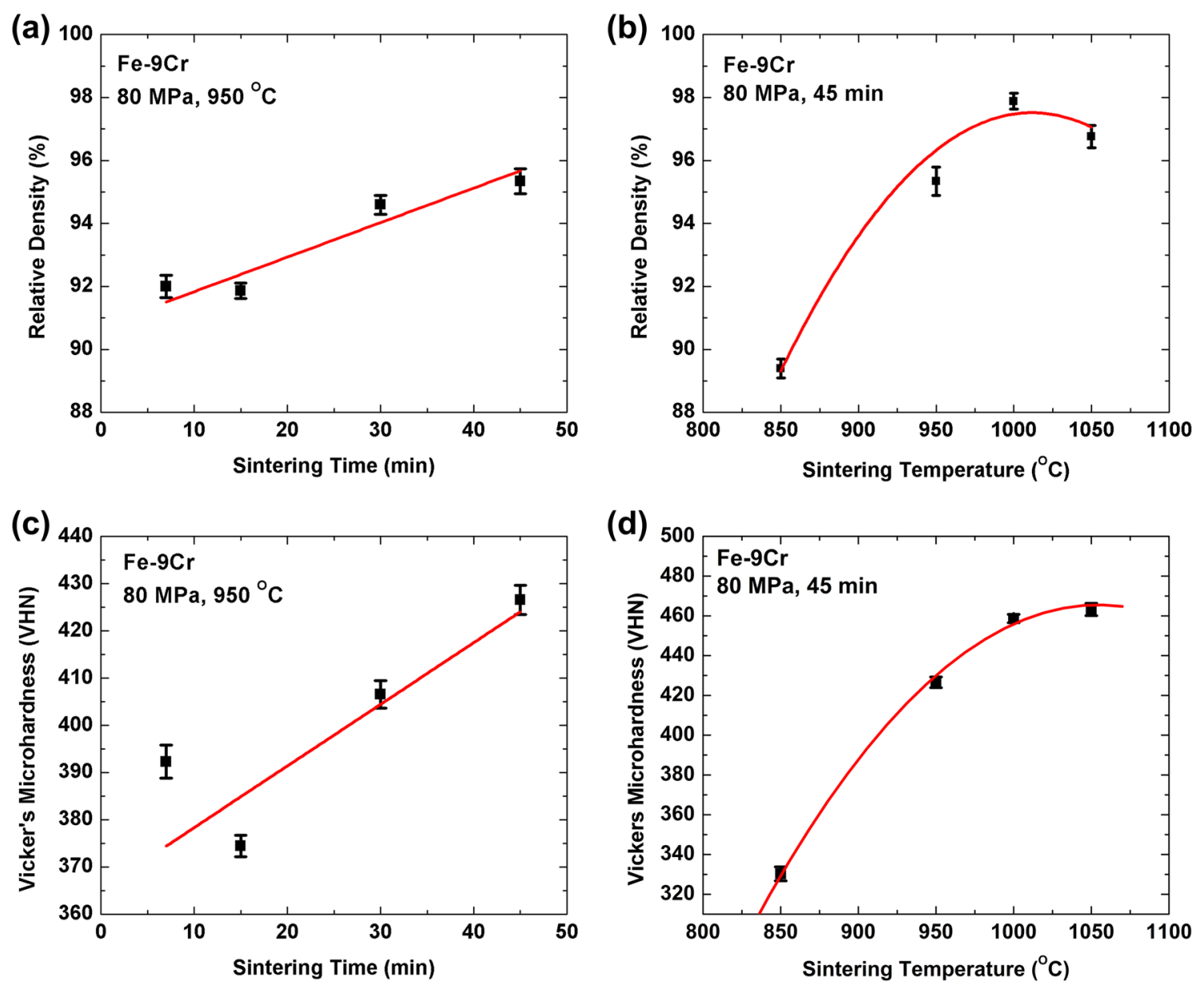

Fig. 3. The variation of relative density of sintered Fe-9Cr samples with (a) sintering time and (b) sintering temperature; and the variation of Vickers microhardness as a function of (c) sintering time and (d) sintering temperature.

the variation of the microhardness of the samples with sintering time. Four sintering times $(7 \mathrm{~min}$, $15 \mathrm{~min}, 30 \mathrm{~min}$, and $45 \mathrm{~min}$ ) were selected, all of which were carried at a constant temperature of $950^{\circ} \mathrm{C}$. The trend shows an increase in microhardness with increasing sintering time. The reason behind this is likely that, with increasing sintering time, the powder has more time to become densified because SPS is a diffusion-controlled process. Thus, with densification (i.e., a decrease in porosity) the hardness also increases. Figure 3d shows the variation of microhardness of the samples with sintering temperature. The four sintering temperatures were $850^{\circ} \mathrm{C}, 950^{\circ} \mathrm{C}, 1000^{\circ} \mathrm{C}$, and $1050^{\circ} \mathrm{C}$. The sintering time was $45 \mathrm{~min}$ and the sintering pressure was $80 \mathrm{MPa}$ and were kept constant when operating at different temperatures. The analysis shows that there is an increasing trend in the hardness of the samples up to $1050^{\circ} \mathrm{C}$. The process of densification, being diffusion-controlled, allows the densification rate to increase and in turn increases the hardness. However, the rate of increase in hardness decreases considerably at $1050^{\circ} \mathrm{C}$ because of a combined effect of porosity generation and grain growth.

\section{Microstructural Characteristics}

Figure $4 \mathrm{a}-\mathrm{c}$ shows the SEM imaging of the $\mathrm{Fe}-\mathrm{Cr}$ samples. The specimen sintered at $850^{\circ} \mathrm{C}$ for $45 \mathrm{~min}$ yielded a low density and hardness compared to the others and so we did not carry out any SEM imaging for that sample. Grain size analysis carried out by the mean linear intercept method showed the average grain sizes to be $1.9 \pm 1.0 \mu \mathrm{m}$, $2.0 \pm 1.0 \mu \mathrm{m}$, and $2.5 \pm 1.0 \mu \mathrm{m}$ for the samples sintered for $45 \mathrm{~min}$ at $950^{\circ} \mathrm{C}, 1000^{\circ} \mathrm{C}$, and $1050^{\circ} \mathrm{C}$, respectively. Quantitative energy dispersive spectroscopy at various points on the sample showed the presence of $\mathrm{Cr}$ in the range of $9 \pm 1$ wt.\%, which represents relatively homogeneous distribution of chromium throughout the matrix.

Figure 4d and e shows the TEM images of the SPSed Fe-9Cr samples sintered at $950^{\circ} \mathrm{C}$ and $1000^{\circ} \mathrm{C}$ respectively. Some second phase particles are observed in the matrix. These particles nucleated during BM and undergrown growth during the SPS process. So, Fe-Cr alloy produced is not truly a singlephase solid solution alloy but rather a $\mathrm{Fe}-\mathrm{Cr}$ matrix with $\mathrm{Cr}$-based oxide phases. Note that earlier studies on pure iron undergoing high-energy ball-milling and 

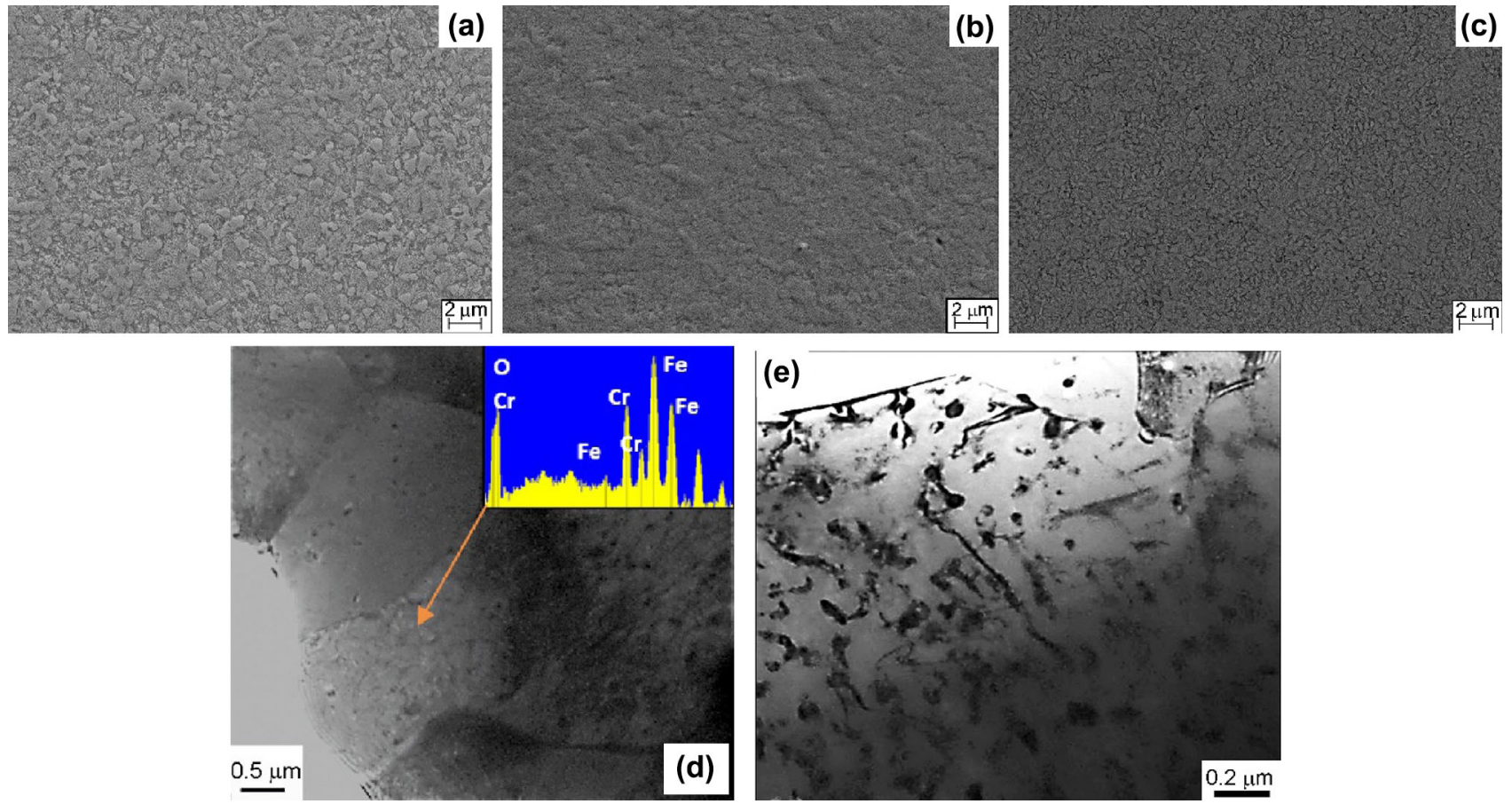

Fig. 4. Secondary electron SEM images of Fe-9Cr alloy specimens 10 -h ball- milled and SPS for 45 min at (a) $950^{\circ} \mathrm{C}$, (b) $1000^{\circ} \mathrm{C}$, and (c) $1050^{\circ} \mathrm{C}$. TEM images of $10-\mathrm{h} \mathrm{BM}$ and SPS for $45 \mathrm{~min}$ at (d) $950^{\circ} \mathrm{C}$, and (e) $1000^{\circ} \mathrm{C}$.

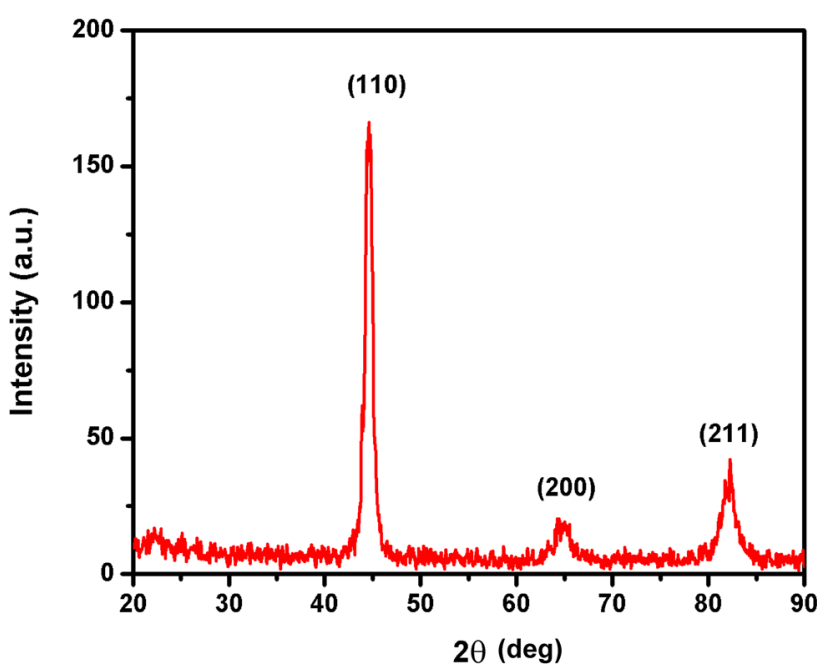

Fig. 5. XRD pattern of the SPS Fe-9Cr sample.

SPS reported the formation of Fe-based oxide particles. Cr having more affinity for oxygen compared to Fe helped in forming Cr oxides. ${ }^{32}$ Also, milling starting with the constituent powder along with some oxygen present already on the surface and ingress of oxygen from the milling environment can help form the precursors of these oxides and they became clearly resolvable in TEM after SPS.

The relative density of the sample after $10-\mathrm{h}$ BM and 45 min sintering at $1000^{\circ} \mathrm{C}$ resulted in the highest density. Further characterization of the Fe-
$9 \mathrm{Cr}$ alloy has been carried out on the samples produced by the aforementioned process route.

Figure 5 shows the XRD pattern of the SPS sample. The pattern shows the predominance of the ferrite phase (BCC lattice structure).

Figure 6a shows the inverse pole figure map of the SPS Fe-9Cr alloy. The orientation of the crystal planes is in the normal direction, i.e., the direction of applied pressure during the SPS process. Figure $6 \mathrm{~b}$ shows the direct pole figures for the three low index family of planes. The grains are found to be randomly oriented throughout the matrix, which confirms that the SPS imparts a fairly random texture. ${ }^{33}$ Figure $6 \mathrm{c}$ shows the grain boundary (GB) misorientation map of the sample and Fig. $6 \mathrm{~d}$ shows the corresponding GB misorientation histogram. Both the figures show that the low-angle GB resolved is only a small fraction of the total grain boundaries. The grain size was found to range from $0.4 \mu \mathrm{m}$ to about $10 \mu \mathrm{m}$,as seen in Fig. 6e. The mean grain size was found to be about $2 \mu \mathrm{m}$, which is similar to that measured from the TEM images.

\section{Evaluation of Compression Properties}

The true stress-true plastic strain curve of the SPS Fe-9Cr in compression is shown in Fig. 7, from which it can be seen that the yield stress was determined to be about $642 \mathrm{MPa}$. Using the wellknown Hollomon's equation, the strain-hardening exponent was calculated to be around 0.12 . 

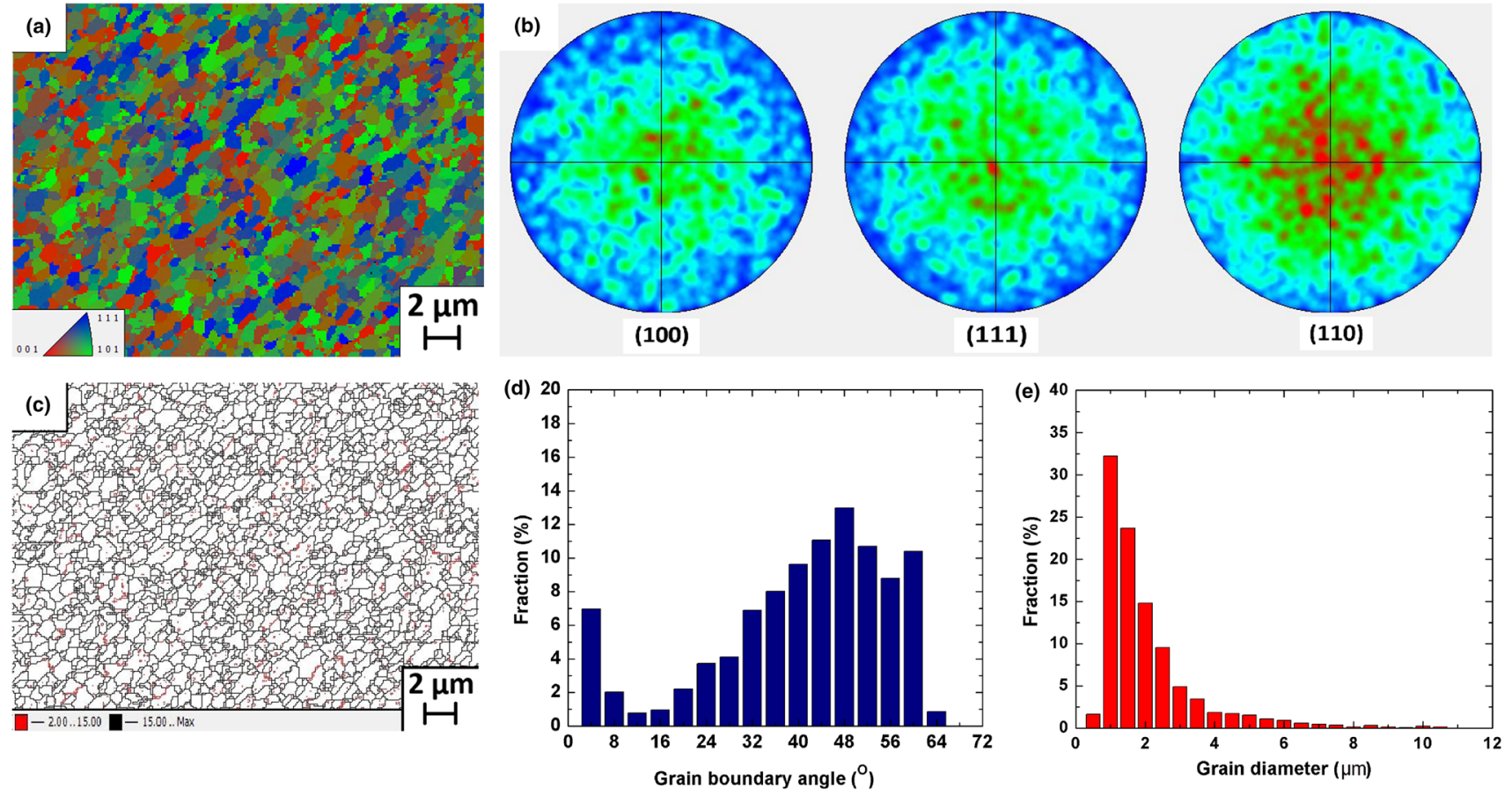

Fig. 6. EBSD results of the SPS $\left(1000^{\circ} \mathrm{C} / 45 \mathrm{~min}\right) \mathrm{Fe}-9 \mathrm{Cr}$ : (a) inverse pole figure map, (b) direct pole figures, (c) grain boundary angle map, (d) grain boundary misorientation distribution histogram, and (e) grain size distribution histogram.

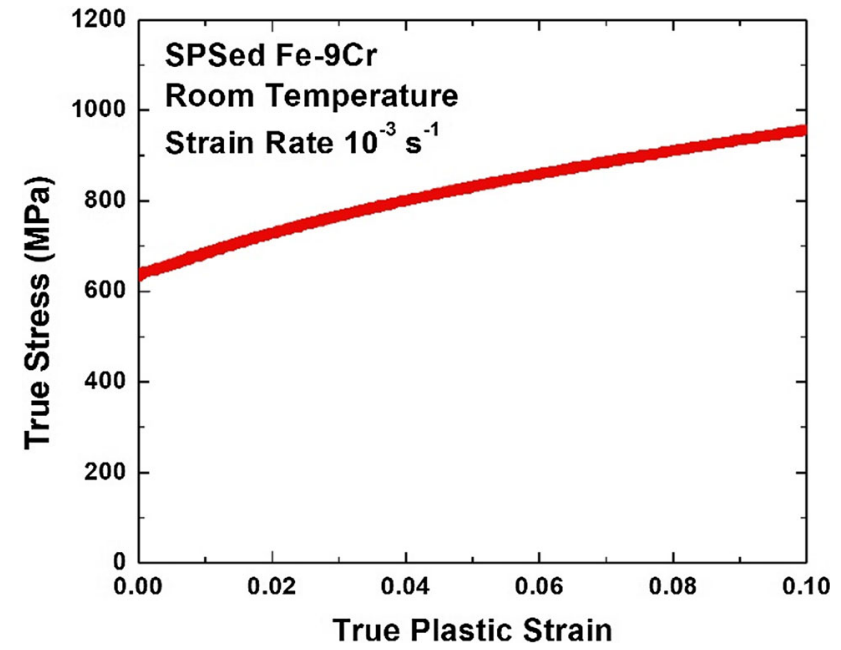

Fig. 7. Compression stress-strain curve (true stress versus true plastic strain) of the Fe-9Cr alloy.

\section{Sintering Kinetics}

In order to understand the SPS kinetics, the model proposed by Young and Cutler ${ }^{34}$ has been used. In their study, non-isothermal equations for volume and GB diffusion have been modified. The equations represent the relationship between the shrinkage $(Y)$ and diffusion coefficient $(D)$, where $c$ represents the heating ramp rate in units of $\mathrm{K} \mathrm{s}^{-134}$ :

$$
\begin{gathered}
\ln \left(Y T \frac{\mathrm{d} Y}{\mathrm{~d} T}\right)=\ln \left(\frac{2.63 \gamma \Omega D_{\mathrm{o}}^{V}}{k a^{3} c}\right)-\frac{Q_{\mathrm{V}}}{\mathrm{RT}} \\
\ln \left(Y^{2} T \frac{\mathrm{d} Y}{\mathrm{~d} T}\right)=\ln \left(\frac{0.71 \gamma b \Omega D_{\mathrm{o}}^{B}}{k a^{4} c}\right)-\frac{Q_{\mathrm{B}}}{\mathrm{RT}}
\end{gathered}
$$

where $Y$ is the linear shrinkage $\left(\Delta l / l_{0}\right), \Omega$ is the volume of vacancy $\left(\mathrm{m}^{3}\right), \gamma$ is the surface energy $(\mathrm{J} /$ $\left.\mathrm{m}^{2}\right), D_{\mathrm{V}}$ is the volume diffusion coefficient given by $D_{\mathrm{V}}=D_{0}^{\mathrm{V}} \exp \left(-Q_{\mathrm{V}} / \mathrm{RT}\right)\left(\mathrm{m}^{2} \mathrm{~s}^{-1}\right), b D_{\mathrm{B}}$ is the product of the GB thickness ' $b$ ' and GB diffusion coefficient ' $D_{\mathrm{B}}$ ' given by $b D_{\mathrm{B}}=b D_{0}^{\mathrm{B}} \exp \left(-Q_{\mathrm{B}} / \mathrm{RT}\right)\left(\mathrm{m}^{3} \mathrm{~s}^{-1}\right), k$ is the Boltzmann constant $(\mathrm{J} / \mathrm{K}), T$ is the temperature (K), $a$ is the particle radius (m) and $t$ is time (s). $Q_{\mathrm{V}}$ and $Q_{\mathrm{B}}$ are the activation energies for volume diffusion and GB diffusion, respectively. The activation energies for volume diffusion and GB diffusion can be obtained from the slope of the plots between $\ln (Y T(\mathrm{~d} Y / \mathrm{d} T))$ versus $1 / T$ and $\ln \left(Y^{2} T(\mathrm{~d} Y /\right.$ $\mathrm{d} T$ )) versus $1 / T$, respectively.

Figure 8a depicts the displacement profile curve of the SPS sample. A constant heating rate has been used during the SPS process. The temperature at which densification begins $\left(T_{\mathrm{s}}\right)$ and the temperature at which maximum densification rate occurs $\left(T_{\max }\right)$ are calculated from the displacement curve and its first derivative, respectively. ${ }^{35}$ It has been found 

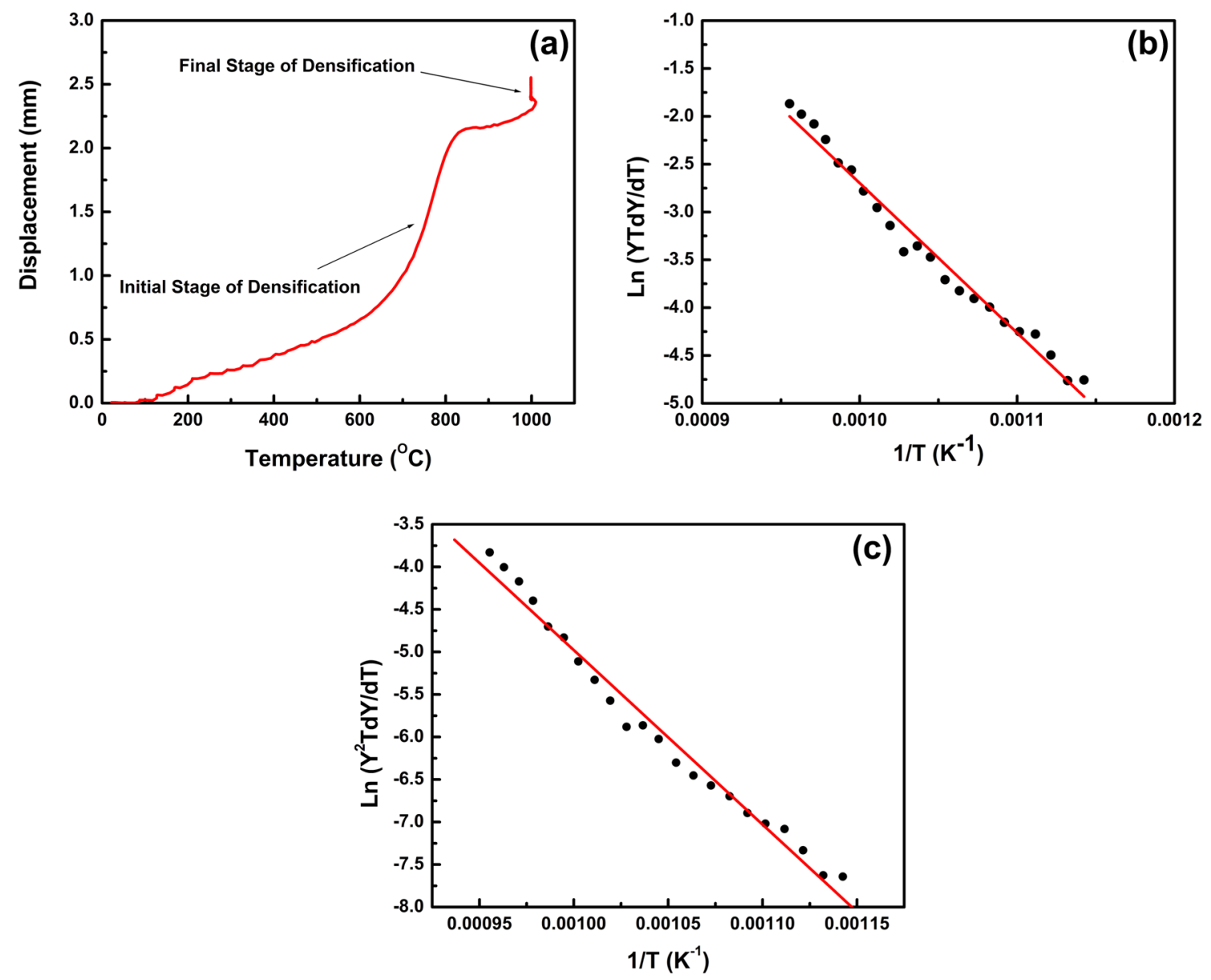

Fig. 8. (a) Displacement profile curve of the SPS Fe-9Cr. Activation energy plots for (b) volume diffusion and (c) grain boundary diffusion.

Table II. Comparison of predicted yield strength and experimental yield strength for the SPS Fe-9Cr alloy

\begin{tabular}{|c|c|c|c|c|c|c|c|c|}
\hline & $\begin{array}{c}\sigma_{\mathbf{P}-\mathbf{N}} \\
(\mathbf{M P a}) \\
\end{array}$ & $\begin{array}{c}\sigma_{\mathbf{S S}} \\
(\mathbf{M P a}) \\
\end{array}$ & $\begin{array}{c}\sigma_{\text {GB }} \\
(\mathbf{M P a}) \\
\end{array}$ & $\begin{array}{c}\sigma_{\mathbf{p}} \\
(\mathbf{M P a}) \\
\end{array}$ & $\begin{array}{c}\sigma_{\boldsymbol{D}} \\
(\mathbf{M P a}) \\
\end{array}$ & $\begin{array}{c}\text { Predicted } \\
\sigma_{y} \text {-Eq. } 4 \\
\text { (MPa) }\end{array}$ & $\begin{array}{c}\text { Predicted } \\
\sigma_{y}-\mathbf{E q} \cdot 5 \\
(\mathbf{M P a})\end{array}$ & $\begin{array}{c}\text { Calculated } \\
\sigma_{y} \text {-experimental } \\
\text { (MPa) }\end{array}$ \\
\hline $\begin{array}{r}\text { Strengthening } \\
\text { mechanisms }\end{array}$ & 50 & 187 & 219 & 94 & 101 & 651 & 594 & 642 \\
\hline
\end{tabular}

that densification starts around $600^{\circ} \mathrm{C}$ and reaches the maximum rate at $825^{\circ} \mathrm{C}$ which is similar to the values obtained by previous studies. ${ }^{36}$

From the slope of the $\ln (Y T \mathrm{~d} Y / \mathrm{d} T)$ versus $1 / T$ plots shown in Fig. 8b, the volume diffusion activation energy for the alloy was estimated to be $130 \pm 3 \mathrm{~kJ} / \mathrm{mol}$. From the slope of the $\ln \left(Y^{2} T \mathrm{~d} Y /\right.$ $\mathrm{d} T$ ) versus $1 / T$ plots shown in Fig. 8c, the GB diffusion activation energy for the alloy was estimated to be $170 \pm 6 \mathrm{~kJ} / \mathrm{mol}$. The activation energies for volume diffusion and GB diffusion of pure $\alpha-\mathrm{Fe}$ are $251 \mathrm{~kJ} / \mathrm{mol}$ and $174 \mathrm{~kJ} / \mathrm{mol}$, respectively. ${ }^{37}$ The nanograin boundary diffusion for Fe powder was estimated by Lee et al. ${ }^{38}$ to be $187 \mathrm{~kJ} / \mathrm{mol}$.
Thus, in the initial phase of sintering, i.e., from $600^{\circ} \mathrm{C}$ to $850^{\circ} \mathrm{C}$, the $\mathrm{GB}$ diffusion is found to be the dominant mechanism. The plausible reason for this could be the preponderance of boundaries due to the nanocrystalline crystallite size produced during BM. However, during SPS, various mechanisms can occur, as reported in previous studies. ${ }^{15}$ In the initial phase, surface diffusion is the dominant mechanism because the electric charge is concentrated mainly on the outer surface of the particles, leading to a capacitive nature between two nearby particles, thus producing enough heat for the surface diffusion to take place. In the later stage, when enough particles have fused together, the volume 
diffusion might come into play, as depicted in Fig. 8a. However, the exact mechanism of the final stage of densification is as yet unknown.

\section{Analysis of Strengthening Mechanisms}

While there are different formalisms of predicting yield strength $\left(\sigma_{y}\right)$ considering superposition of individual strengthening mechanisms, $\sigma_{y}$ is expressed using a linear summation relationship ${ }^{39}$ :

$$
\sigma_{y}=\sigma_{\mathrm{P}-\mathrm{N}}+\sigma_{\mathrm{SS}}+\sigma_{\mathrm{GB}}+\sigma_{\mathrm{P}}+\sigma_{\mathrm{D}}
$$

where $\sigma_{\mathrm{P}-\mathrm{N}}$ is the friction stress (Peierls-Nabarro stress), $\sigma_{\mathrm{SS}}$ is the solid solution strengthening, $\sigma_{\mathrm{GB}}$ is the $\mathrm{GB}$ strengthening, $\sigma_{\mathrm{P}}$ is the precipitation strengthening and $\sigma_{\mathrm{D}}$ is the dislocation strengthening. Another way of expressing $\sigma_{y}$ is based on the assumption that the obstacle strengths for dislocation strengthening and particle strengthening are of similar magnitude, and hence a non-linear additivity rule, as shown in Eq. 5 . $^{40}$

$$
\sigma_{y}=\sigma_{\mathrm{P}-\mathrm{N}}+\sigma_{\mathrm{SS}}+\sigma_{\mathrm{GB}}+\sqrt{\sigma_{\mathrm{P}}^{2}+\sigma_{\mathrm{D}}^{2}}
$$

In this study, the value of $\sigma_{\mathrm{P}-\mathrm{N}}$ for pure iron is taken as $50 \mathrm{MPa}^{41}$ The value of $\sigma_{\mathrm{SS}}$ is calculated using the following equation ${ }^{42}$ :

$$
\sigma_{\mathrm{SS}}=\sum A_{i} C_{i}
$$

where $A_{i}$ is the strengthening coefficient of alloying elements: $C(5544 \mathrm{MPa} / \mathrm{wt} . \%)^{43}$ and $\mathrm{Cr}(8.5 \mathrm{MPa} /$ wt.\%). ${ }^{44} C_{i}$ is the wt.\% of the alloying elements.

The value of $\sigma_{\mathrm{GB}}$ is calculated using the HallPetch equation: ${ }^{41}$

$$
\sigma_{\mathrm{GB}}=k d^{-\frac{1}{2}}
$$

where $k$ is a constant $\left(310 \mathrm{MPa} \mu \mathrm{m}^{1 / 2}\right)^{41}$ and $d$ is average grain diameter as calculated $(2 \mu \mathrm{m})$.

The value of $\sigma_{\mathrm{P}}$ is calculated using the OrowanAshby equation: ${ }^{45}$

$$
\sigma_{\mathrm{p}}=\frac{0.538 G b \sqrt{f}}{d p} \ln \left(\frac{d p}{2 b}\right)
$$

where $G$ is the shear modulus of iron ( $60 \mathrm{GPa}), b$ is the Burgers vector $(0.248 \mathrm{~nm}), f$ is the volume fraction of the chromium oxide particles (0.05) and $d_{\mathrm{p}}$ is the average particle diameter $(0.1 \mu \mathrm{m})$.

The strengthening $\left(\sigma_{\mathrm{D}}\right)$ due to the dislocation density is obtained by the following equation ${ }^{46}$ :

$$
\sigma_{\mathrm{D}}=\alpha M G b \sqrt{\rho}
$$

where $\alpha$ is a numerical constant which is usually taken as $0.3-0.6, M$ Taylor's factor (2.78 for BCC), $G$ is the shear modulus, $b$ the Burgers vector, and $\rho$ the dislocation density $\left(0.89 \times 10^{14} \mathrm{~m}^{-2}\right)$ as evaluated using the following equation ${ }^{47,48}$ :

$$
\rho=2 \sqrt{3} \frac{\left\langle\xi^{2}\right\rangle^{0.5}}{d \times b}
$$

where $\left\langle\xi^{2}\right\rangle^{0.5}$ is the mean lattice strain $(0.013 \%)$ obtained from the XRD pattern (by the WilliamsonHall method) of sintered specimens; $d$ and $b$ have already been defined.

The predicted yield strength values are included in Table II alongside the estimated individual strengthening mechanism contributions. The predicted yield strength from the linear superposition rule came to be around $651 \mathrm{MPa}$, which is closer to the experimentally determined value $(642 \mathrm{MPa})$, while the non-linear superposition resulted in a yield strength value of $594 \mathrm{MPa}$.

Previously, $\mathrm{Fe}-9 \mathrm{Cr}$ alloys have been made via casting. ${ }^{49-51}$ The cast structures had microhardness of about $390 \mathrm{VHN}$, although it had a martensitic structure with precipitates of $\mathrm{MX}, \mathrm{M}_{23} \mathrm{C}_{6}$, Laves phase, and $Z$ phase. But due to the very small grain size of the sintered sample compared to that of the cast sample (around $20 \mu \mathrm{m}$ ), the hardness was higher than that of the cast alloy. Large elongated segregations of Cr-rich phases have been seen in those alloys. ${ }^{52}$ However, after consolidation by SPS, we could not find any such martensitic structure as the material under study has a very low carbon content. EDS analysis has been carried out on various regions of the consolidated sample, but no Cr-rich segregations have been found. Fe9Cr ODS steel has also been prepared by the BM process and, for $10-\mathrm{h}$ and $20-\mathrm{h}$ BM times, the mean powder size is close to what we achieved, as reported by Xu et al. ${ }^{53}$ Heintze et al. ${ }^{23}$ reported that $\mathrm{Fe}-9 \mathrm{Cr}$ ODS produced by a combined process of BM, SPS and HIP had a relative density level of $98.1 \%$, which is quite close to the $97.9 \%$ that we obtained by BM and SPS.

\section{CONCLUSION}

The main objective of this study was to develop a fabrication route for the $\mathrm{Fe}-9 \mathrm{Cr}$ model alloy. This work involved optimization of the BM and SPS parameters.

1. The high-energy ball-milling of $\mathrm{Fe}-9 \mathrm{Cr}$ samples for longer durations resulted in decreased powder size and nanocrystalline crystallite size in the milled powder.

2. With increasing milling time, the powder size decreased and the powder size distribution also became narrower. The lattice parameter showed only slight variation with changes in BM time.

3. During SPS with increasing sintering temperature, the diffusion process increased, but at a higher temperature the densification process became almost constant. A BM time of $10 \mathrm{~h}$, SPS temperature of $1000^{\circ} \mathrm{C}$ and sintering time of 45 min have been found to be optimum for producing the $\mathrm{Fe}-9 \mathrm{Cr}$ alloy.

4. TEM analysis revealed the presence of Cr-based fine oxide particles in the matrix, which adds to the high hardness of the material due to particle hardening. 
5. EBSD analysis showed no preferred texture throughout the alloy.

6. A kinetics study indicates that, in the initial stage of SPS, GB diffusion is the dominant mechanism for the consolidation process.

7. Analysis of strengthening mechanisms using a linear superposition revealed the best correlation between the predicted yield strength and the experimentally obtained yield strength.

\section{ACKNOWLEDGEMENTS}

The work presented here is supported by the INL Laboratory Directed Research \& Development (LDRD) Program under DOE Idaho Operations Office Contract DE-AC07-05ID14517. AK and IC gratefully acknowledge Dr. Thomas Williams for help with the XRD work. We are also thankful to Sean Instasi and Nathan Jerred for assistance with material processing.

\section{REFERENCES}

1. A. Kohyama, A. Hishinuma, D.S. Gelles, R.L. Klueh, W. Diets, and K. Ehrich, J. Nucl. Mater. 138, 233 (1996).

2. F.A. Garner, M.B. Toloczko, and B.H. Sencer, J. Nucl. Mater. 276, 123 (2000).

3. R.L. Klueh and D.H. Harries, High-Chromium Ferritic and Martensitic Steels for Nuclear Applications, Vol. 3 (West Conshohocken: ASTM International, 2001).

4. B. Raj, S.L. Mannan, P. Rao, and M.D. Mathew, Sadhana 7, 527 (2002).

5. C. Suryanarayana, Prog. Mater Sci. 46, 1 (2001).

6. C.L. Chen and Y.M. Dong, Mater. Sci. Eng. A 528, 8374 (2011).

7. C. Suryanarayana, E. Ivanov, and V.V. Boldyrev, Mater. Sci. Eng. A 304, 151 (2001).

8. J.B. Fogagnolo, F. Velasco, M.H. Robert, and J.M. Torralba, Mater. Sci. Eng. A 342, 131 (2003).

9. M. Zawrah and L. Shaw, Mater. Sci. Eng. A 355, 37 (2003).

10. R. Juarez, J.J. Sunol, R. Berlanga, J. Bonastre, and L. Escoda, J. Alloys Compd. 434, 472 (2007).

11. Z. Oksiuta and N. Baluc, J. Nucl. Mater. 386, 426 (2009).

12. H.J. Fecht, Nanostruct. Mater. 6, 33 (1995).

13. O. Guillon, J. Gonzalez-Julian, B. Dargatz, T. Kessel, G. Schierning, J. Rathel, and M. Herrmann, Adv. Eng. Mater. 16,830 (2014).

14. KU Leuven, SPS Process Modeling (KU Leuven Department of Materials Engineering). https://www.mtm.kuleuven.be/O nderzoek/Ceramics/research/sintering/spark-plasma. Accessed 27 Sept 2018

15. M. Suárez, A. Fernández, J.L. Menéndez, R. Torrecillas, H. U. Kessel, J. Hennicke, R. Kirchner, and T. Kessel, Challenges and Opportunities for Spark Plasma Sintering: A Key Technology for a New Generation of Materials in Sintering Applications (Burcu Ertuğ, IntechOpen, 2013). http://dx.doi. org/10.5772/53706. Accessed 27th Sept 2018.

16. R. Orru, R. Licheri, A.M. Locci, A. Cincotti, and G. Cao, Mater. Sci. Eng. R 63, 127 (2009).

17. E. Olevsky, S.Y. Kandukuri, and L. Froyen, J. Appl. Phys. 102, 114913 (2007).

18. L. Toualbi, C. Cayron, P. Olier, J. Malaplate, M. Praud, M.H. Mathon, D. Bossu, E. Rouesne, A. Montani, R. Logé, and Y. de Carlan, J. Nucl. Mater. 428, 47 (2012).

19. S. Noh, A. Kimura, and T.K. Kim, Fusion Eng. Des. 89, 1746 (2014).

20. S.A. Briggs, P.D. Edmondson, K.C. Littrell, Y. Yamamoto, R.H. Howard, C.R. Daily, K.A. Terrani, K. Sridharan, and K.G. Field, Acta Mater. 129, 217 (2017).
21. S. Li, Y. Wang, X. Dai, F. Liu, J. Li, and X. Wang, J. Nucl. Mater. 478, 50 (2016).

22. K. Ono, K. Arakawa, H. Shibasaki, H. Kurata, I. Nakamichi, and N. Yoshida, J. Nucl. Mater. 329, 933 (2004).

23. C. Heintze, M. Hernandez-Mayoral, A. Ulbricht, F. Bergner, A. Shariq, T. Weissgarber, and H. Frelinghaus, J. Nucl. Mater. 428, 139 (2012).

24. M. Zakeri and A. Nazari, Neural Comput. Appl. 21, S723 (2012).

25. J.B. Nelson and D.P. Riley, Proc. Phys. Soc. 57, 160 (1945).

26. G.K. Williamson and W.H. Hall, Acta Metall. 1, 22 (1953).

27. Y. Zhenhua, X. Weihao, Y. Ming, and P. Qianyun, J. Nucl. Mater. 403, 198 (2010).

28. S. Pasebani, I. Charit, D.P. Butt, and J.I. Cole, J. Nucl. Mater. 434, 282 (2013).

29. X.T.A. Chu, B.N. Ta, L.T.H. Ngo, M.H. Do, P.X. Nguyen, and D.N.H. Nam, J. Electron. Mater. 45, 2311 (2016).

30. R.K. Khatirkar and B.S. Murty, Mater. Chem. Phys. 123, 247 (2010)

31. A.R. Denton and N.W. Ashcroft, Phys. Rev. A 43, 3161 (1991).

32. B. Arh and F. Tehovnik, Mater. Technol. 41, 203 (2007).

33. B. Srinivasarao, K. Oh-ishi, T. Ohkubo, and K. Hono, Acta Mater. 57, 3277 (2009).

34. W.S. Young and I.B. Cutler, J. Am. Ceram. Soc. 53, 659 (1970).

35. J. Guyon, A. Hazotte, J.P. Monchoux, and E. Bouzy, Intermetallics 34, 94 (2013)

36. S. Pasebani, I. Charit, D.P. Butt, J.I. Cole, Y. Wu, and J. Burns, Adv. Eng. Mater. 18, 324 (2016).

37. H.J. Frost and M.F. Ashby, Fundamental Aspects of Structural Alloy Design (Boston: Springer, 1977).

38. J.S. Lee, J.P. Choi, and G.Y. Lee, Materials 6, 4046 (2013).

39. D.R. Lesuer, C.K. Syn, and O.D. Sherby, Mater. Trans. 47, 1508 (2006).

40. A. Sittiho, V. Tungala, I. Charit, and R.S. Mishra, J. Nucl. Mater. 509, 435 (2018).

41. W.C. Leslie, Metall. Trans. 3, 5 (1972).

42. S. Schmauder and C. Kohler, Mater. Sci. 50, 1238 (2011).

43. G.E. Totten, L. Xie, and K. Funatani, Handbook of Mechanical Alloy Design (New York: Marcel Dekker, 2003).

44. J. Wang, W. Yuan, R.S. Mishra, and I. Charit, J. Nucl. Mater. 432, 274 (2013).

45. M.A. Altuna, A. Iza-Mendia, and I. Gutierrez, Metall. Mater. Trans. A 43, 4571 (2012).

46. W. Li, H. Xu, X. Sha, J. Meng, W. Wang, C. Kang, X. Zhang, and Z. Wang, Fusion Eng. Des. 137, 71 (2018).

47. K.G. Raghavendra, A. Dasgupta, and P. Bhaskar, Powder Technol. 287, 190 (2016).

48. M. Mhadhbi, M. Khitouni, L. Escoda, J.J. Suñol, and M. Dammak, J. Nanomater. 2010, 712407 (2010).

49. O. Boshko, O. Nakonechna, N. Belyavina, M. Dashevskyi, and S. Revo, Adv. Powder Technol. 28, 964 (2017).

50. Z. Hou, Study of Precipitation in Martensitic Fe-C-Cr Alloys During Tempering: Experiments and Modelling (Royal Institute of Technology, Stockholm, 2015), https://www.div a-portal.org/smash/get/diva2:866846/FULLTEXT01.pdf. Accessed 27th Sept 2018.

51. T. Shrestha, S.F. Alsagabi, I. Charit, G.P. Potirniche, and M.V. Glazoff, Metals 5, 131 (2015).

52. V. Kuksenko, Model Oriented Irradiation Experiments in $\mathrm{Fe}$-Cr Model Alloys, Doctoral Thesis in Materials Science, Université de Rouen, France, 2011.

53. H. Xu, Z. Lu, D. Wang, and C. Liu, Nucl. Mater. Energy 7, 1 (2016).

Publisher's Note Springer Nature remains neutral with regard to jurisdictional claims in published maps and institutional affiliations. 